week. ${ }^{3}$ The percentage rises after this time, but again there is much variation in individual cases. Further analyses of the liquor chemically are being made to try to improve accuracy in intepretation, but these too are likely to show much variability. The oldest method of all is probably radiography in the hope of showing centres of ossification. These can be obscured by maternal shadows, but the lower femoral epiphysis appears at about 36 weeks and that of the upper end of the tibia at 40 weeks. They too are variable.

Two things are wanted. One is a measure of the weight of the fetus in an individual case at any time in pregnancy. So often it is the weighi of the fetus which determines whether induction of labour or caesarean section should be performed. The second is an estimate of the time that has elapsed from the beginning of pregnancy when the date of the last menstrual period is not known with reasonable accuracy. It should be noted that the modern tests of placental function all require that the gestational age should be known. In some cases, therefore, it might be wise for the family doctor to advise a woman to keep a note of her periods.

Time and growth are fundamentals in biology, nowhere better exemplified than in pregnancy. Much is known about them in the statistical sense, comparatively little in the individual. But this is what is needed in clinical practice.

\section{Progress in Physiotherapy}

Soon after the renewal of interest in massage or "medical rubbing" at the end of the nineteenth century the Society of Trained Masseuses was founded to regularize this treatment. In 1900 the society became incorporated, and in the next two decades it introduced examinations in remedial exercises and in medical electricity. By 1920 the society had merged with the Institute of Massage and Remedial Gymnasts, and in that year it was granted a charter to become "The Chartered Society of Massage and Medical Gymnastics." At this time men were first admitted, and landmarks since include the adoption of the name "Chartered Society of Physiotherapy" in 1942, and the initiation of state registration in 1960.

Now, 50 years after the granting of its royal charter, there are just over 30,000 members of the society, of whom just under 10,000 are practising in the United Kingdom. Last year 740 physiotherapists qualified from the 38 training schools. What these statistics do not show is that there is a shortage of trained staff physiotherapists, and that there are not enough teachers or suitable applicants for places in physiotherapy schools. The Chartered Society is playing an active part in helping to improve the situation, and supervises training, examination, and registration. The national shortage of physiotherapists is estimated to be about $20 \%$. Nevertheless, this shortage is patchy, and it is made worse by a "wastage" of trained physiotherapists, some of whom marry or take other posts outside physiotherapy. This wastage would certainly be lessened by improvement of the career and salary structure of the profession, which lags far behind other fields open to young women.

With the current shortage of physiotherapy teachers possibly the training schools could be reorganized on a more

1 British Medical fournal, 1966, 1, 253 .
2 Nichols, P. J. R., and Howell, B., Rheumatology and Physical Medicine,
1970, 10, 321. efficient basis. Most physiotherapy schools have grown where there has been a demand for therapists, and the reduplication of small schools is wasteful of teachers' time. It has been proposed that there should be fewer schools with a larger and less frequent intake, and that teaching should be shared with other auxiliary medical professions or with medical schools. Logically, training schools should be organized at regional centres so that both training and staffing can be spread more uniformly over the country.

The value of physiotherapy for patients in rheumatology, orthopaedic, neurology, and intensive care units is not questioned, and often a demand for a 24-hour service is being met. Nevertheless, the responsibility for the efficient use of physiotherapists' time rests with doctors. Though few medical students or junior doctors have any illusions about the social benefits of physiotherapists, few have been taught about the uses and abuses of physiotherapy itself. Equally, good clinical trials of the effectiveness of physiotherapeutic treatment have been scarce, though every clinician has the responsibility to establish that his prescriptions are effective. Recently a lead has been given by the British Association of Physical Medicine and Rheumatology with trials of treatment of pain in the neck and arm, ${ }^{1}$ and of preoperative and postoperative physiotherapy, ${ }^{2}$ the former with the help of leading physiotherapists and the latter with the co-operation of the Chartered Society. The support of this kind of project by the Department of Health and Social Security shows the growing interest in the cost-effectiveness of various types of physiotherapy, and there seems little doubt that the results of these will support the present trend away from electrical treatment towards physical methods.

The medical pharmacopoeia could be greatly reduced in size if only drugs of proved effectiveness were prescribed; similarly, the bulk of work and consequent shortage of physiotherapists might well be reduced if prescriptions were confined to those of established value.

\section{Absence from Work}

Increasing absence from work attributed to sickness is causing mounting concern in industry and commerce. Three hundred and ten million working days of National Insurance sickness benefit supported by medical certificates are now being paid in this country each year, an increase of about $15 \%$ in 15 years. In addition to the cost of sickness benefit $(£ 300 \mathrm{~m}$. per annum), the country loses the value of the absentee's production and his contribution to income tax and to the National Insurance fund.

The chronic sick (the 1 to $2 \%$ of the insured population who have been sick for more than a year) account for a third of the total working days lost and for some of the increase in sickness absence in recent years. Apart from the chronic sick the increase in sickness absence has occurred mainly in the younger people. ${ }^{1}$ In the 15 -year period the average number of spells of absence per person under 45 has increased by about $80 \%$ and the average number of days by $90 \%$, whereas there has been little change in people of over $45 .^{1}$ The National

\footnotetext{
British Rubber Manufacturers' Association, Abridged Proceedings of the National Health Conference, London, B.R.M.A., 1969.

Raffle, A., Proceedings of the Royal Society of Medicine, 1970, 63, 731.

3 Froggatt, P., British Fournal of Industrial Medicine, 1970, 27, 199.

4 Froggatt, P., British fournal of Industrial Medicine, 1970, 27, 211.

5 Froggatt, P., British Fournal of Industrial Medicine, 1970, 27, 297.
} 
Insurance figures of sickness benefit do not include spells of absence of three days or less, which do not attract benefit and are usually uncertificated. Industrial experience suggests that these spells have increased more than the certificated spells and that the change is even greater among younger persons.

Managers recognize that some members of the staff are more likely to have spells of sickness absence than others. Typical figures ${ }^{2}$ show that $28 \%$ of men have no spells of absence in the year, whereas $31 \%$ have at least three spells and $7 \%$ at least six spells, and the same individuals appear to repeat their same pattern in consecutive years. Some are more liable to "sickness absence" than others, and this appears to be particularly true of short-term absence. It would be a great advantage if those who were liable to have more than average numbers of short-term spells of sickness absence, which are very disrupting to industry, could be identified by other factors.

Professor P. Froggatt ${ }^{3-5}$ has now analysed the distributions of one-day and two-day absences among 2,300 male and female workers, both salaried and hourly paid, in two light engineering works and two Government departments in Northern Ireland. He tested the abilities of five hypotheses to explain the distributions-"chance," "proneness," and three of "true contagion." From closely reasoned arguments he draws the conclusion that "proneness" (a stable liability to absence) plus several unquantifiable factors constant for each individual over the period of study largely explain the data. But he emphasizes that some of the other hypotheses cannot be entirely rejected. Froggatt suggests that two-day absences are more like long-term sickness absence (and hence have "medical causes"), whereas onc-day absences appear to have "non-medical" causes. But as one-day and two-day absences are themselves associated, other factors should operate. He concludes that "proneness" does successfully explain the pattern of short-term sickness absence of the people he studied.

In attempting to identify and measure the characteristics of the people prone to one-day absence and those prone to twoday absence he shows that the strongest absence pattern in the period he studied is, for each group, related to their sickness absence experience in previous periods. A reasonable prediction of the average future experience, especially for one-day absences, could be made from study of the past, though perhaps not to an extent which would justify executive action. He suggests that, whatever reasons the workers concerned may give for them, short-term absences may simply be the overt expression of a desire to work discontinuously. And this inclination, though it can be mitigated in some circumstances, will still be stronger in some individuals than others. This work is a valuable confirmation of subjective impressions of managers and occupational physicians.

Froggatt implies that the pattern of one-day and two-day absences in individuals is immutable, and this is protably true when it has been established for many years. In these circumstances the individual's excessive sickness absence must be accepted or employment terminated. However, there is a small group of them in whom, after investigation, no apparent cause for repeated absences can be found but who are unaware of the number of their absences. ${ }^{2}$ The sickness absence of some of these people will diminish after explanation, especially if they are seen within a year or 18 months of the beginning of their poor pattern of absence. Perhaps the manager, the family doctor, and occupational physician can collatorate in identifying early those who are starting to have frequent short-term absences to try to reverse the trend before it becomes an established pattern. The manager and the occupational physician can also collaborate in trying to find out reasons for the proclivity to discontinuous work in particular occupations. Are capacities being underemployed? Are workers being made to feel inadequate? Are their failures and successes going unrecognized?

\section{In Time of Need}

Arranging charitable help for their patients is something most doctors have been concerned with at some time in their professional lives. Less commonly, fortunately, a doctor or his family may have to seek such help themselves. Nevertheless enough medical families run into unforeseen difficulties to prompt a steady stream of requests to the profession's own charities. Until now the largest of the funds devoted to helping doctors and their families has been the Royal Medical Benevolent Fund, with its offspring, the Ladies' Guild. The Epsom College Foundation supports pensioners as well as schoolchildren, and the B.M.A. too has its established charities-the Sir Charles Hastings and Dain Funds. ${ }^{1}$ In addition there are a number of local charities of varying size which do excellent work.

A newcomer is rare, and the launching of the Cameron Fund $^{2}$ with a capital of $£ 800,000$ is a welcome arrival. The fund's capital, which was the amount outstanding when the general practitioners' group practice loan fund was wound up, should provide it with the largest investment income of all the medical charities. The trustees are fortunate in starting life with such a substantial foundation, and it will leave them free, at least in the early stages, to concentrate on their objective of assisting family doctors and their families in need.

Of the two basic functions of a charity-raising money, and distributing it fairly-the first is usually the more publicized. However, identifying suitable applicants and assessing their real needs are obviously as important and can be surprisingly difficult. Smaller funds are especially vulnerable, since they cannot really devote suffic ${ }_{1}$ ent money to employing staff on what is often a delicate and time-consuming task. Furthermore, the financial limitations of a small charity probably make the trustees reluctant to advertise its availability too vigorously.

The country's economic inflation now makes it imperative that the money available should be used to greatest effect. There is much informal co-operation already among the existing national and local medical funds. The arrival of the Cameron Fund and the threat of continued inflation prompts the question whether more co-ordination in administration might usefully be achieved, particularly in the expert assessment of applications. And perhaps the profession itself could play a greater part locally on behalf of all the charities by identifying and assessing those in need.

These are only a few of the problems which will no doubt be considered by the Cameron Fund's trustees. They will have behind them the good wishes of the whole profession, and at the same time they will be the first to agree that their presence will not lessen the importance of existing charities nor the need to support them. With the approach of Christmas doctors will no doubt wish to help with their customary generosity all the funds which help members of the profession and their dependants in time of need. In particular readers are reminded of the R.M.B.F.'s annual "Christmas Gifts" appeal (see letter p. 435).

${ }^{1}$ British Medical fournal, Supplement 1969, 3, 107.

'British Medical fournal, 1969, 3, 6. 